\title{
OS PROCESSOS SUBJETIVOS E OS JOGOS DE VERDADE DA PSICANÁLISE FRENTE À TRANSFORMAÇÃO DO LUGAR DO PAI
}

Maria Regina dos Santos Prata

Pós-doutora em

Teoria Psicanalítica, IP/UFRJ; doutora

em Saúde Coletiva, IMS/Uerj;

mestre em Teoria Psicanalítica, IP/ UFRJ; membro do Espaço Brasileiro de Estudos Psicanalíticos.
RESUMO: Discutem-se aqui as relações entre os processos subjetivos e as formas de sofrimento a eles associados, levando em consideração o lugar do pai circunscrito por Freud e Lacan e suas transformações na contemporaneidade. A intenção é indicar as mudanças na subjetividade contemporânea, em particular em relação ao lugar atribuído ao pai na sociedade disciplinar e na configuração social da atualidade. Com isso, busca-se estabelecer articulações entre as novas relações de poder e a produção da subjetividade na clínica da psicanálise.

Palavras-chave: Freud e Lacan, lugar do Pai, sociedade disciplinar, contemporaneidade.

ABSTRACT: Psychoanalysis's subjective processes and truth games in the transformation of the father's place. This paper discusses the relations among subjective processes and forms of suffering associated with them, considering the father's place as described by Freud and Lacan, and its changes in contemporaneity. It aims to indicate the changes in contemporary time, especially in relation to the place conferred to the father in the disciplinary society and in the present social configuration. Thus it tries to establish articulations among the new relations of power and subjectivity's production in the psychoanalytic clinic.

Keywords: Freud \& Lacan, Father's Place, disciplinary society, contemporaneity. 


\section{INTRODUÇÃO}

Este artigo discute as relações entre os processos subjetivos e as formas de sofrimento a eles associados, levando em consideração o lugar do pai circunscrito por Freud e Lacan. A intenção é discutir as mudanças na subjetividade contemporânea e seu deslocamento na atualidade, em particular com relação ao lugar atribuído ao pai na sociedade disciplinar (FOUCAULT, 1977).

Atravessada por um projeto normativo de constituição de um homem conveniente à engrenagem social, a psicanálise recebe em sua clínica os efeitos das exigências na subjetividade de adequação a um determinado modelo de conduta. Do surgimento da psicanálise, no final do século XIX, até o início do século XXI, essas exigências e demandas foram se transformando em conjunto com as mutações sociais e as novas relações de poder que foram se constituindo.

Do final do século XVIII até meados do século XX, o homem modelo deveria ter seus modos de vida e de ser ajustados ao funcionamento da ordem econômica capitalista; seu corpo se transformou e aperfeiçoou a fim de que tivesse uma utilidade social. Assim, tratava-se de preparar o homem para que seu corpo, seu trabalho e seu tempo atendessem às demandas crescentes da produção econômica. Nessa medida, o poder disciplinar buscava regular os corpos, produzindo um modelo humano de adequação social. No caso da psicanálise, a questão seria discutir de que modo esse modelo, presente no campo das ciências humanas e das ciências da saúde, está associado a determinadas formas de sofrimento subjetivo.

As técnicas de aperfeiçoamento do poder disciplinar sobre o corpo se articularam a um projeto de normalização social que se fez presente nas instituições, tais como a família e a escola, e se reiterou nas microrrelações (FOUCAULT, 1977). E para que a disciplina mantivesse sua eficiência, deveria ser reproduzida nas instituições pelas quais passavam os indivíduos no decorrer de suas vidas. ${ }^{1}$

$\mathrm{Na}$ família Ocidental, o poder disciplinar estava diretamente associado ao lugar ocupado pelo pai e às relações estabelecidas entre os integrantes da família. Dito de outro modo, na organização familiar da sociedade disciplinar os lugares da mãe, do pai e dos filhos eram distribuídos segundo as funções específicas que deveriam ser exercidas por cada um. O pai era o representante interno da lei social, cabendo-lhe também a função de provisão material das necessidades dos filhos e da esposa. A mãe cuidava da organização privada do lar e do acompanhamento imediato dos filhos. A estes últimos, cabia a obediência. Todos estavam interligados na rede do poder.

\footnotetext{
${ }^{1}$ Para evitar uma possível confusão entre terminologias de campos específicos de saber, optei aqui por restringir as categorias de homem e indivíduo quando referidas a uma discussão mais própria ao campo social e as categorias de sujeito e subjetividade quando referidas ao campo de interesse desse artigo, ou seja, a psicanálise.
} 
Uma vez que os sujeitos eram veículo de transmissão do poder e atravessados por essa mesma transmissão, eles também sofriam os efeitos de adequação aos padrões de conduta. Assim, pode-se dizer que as formas de sofrimento patentes no início do século XX indicavam justamente a eficiência do poder disciplinar sobre os corpos.

Assim, é fundamental destacar a importância atribuída pela psicanálise ao lugar ocupado pelo pai e ao que denominou de complexo de Édipo, bem como as relações deste saber com as categorias de renúncia, de culpa e de lei.

De forma geral, o Édipo pode ser entendido na psicanálise como a representação inconsciente por meio da qual a criança expressa o desejo sexual pelo genitor do sexo oposto e a hostilidade pelo genitor do mesmo sexo. Esta representação pode ser invertida e expressar o desejo pelo genitor do mesmo sexo e a hostilidade ao outro, sendo que a mistura entre as duas modalidades de representações configura o Édipo completo (ROUDINESCO \& PLON, 1998). Considerando que seu desenrolar, tanto em Freud quanto em Lacan, está ligado aos destinos das formas de sofrimento subjetivo, pode-se dizer que o Édipo é uma noção central associada à estruturação do sujeito no discurso psicanalítico.

Em Freud, o sujeito está em conflito consigo mesmo, ocupado com os interditos que o fazem renunciar ao desejo e com o sentimento de culpa por desobedecê-los, tendo internalizado a vigilância da disciplina e da lei. Em Lacan, a culpa é erigida pela "angústia de castração": para sair da infância e ser adulto, não há outra escolha a não ser confrontar-se com a interdição, experimentar o corte, a fim de diferenciar o pai imaginário, que a criança crê todo poderoso, e o pai simbólico, da encarnação da lei. Tornar-se adulto equivale à angústia de si que é inerente à liberdade do sujeito (EHRENBERG, 1998).

Foi justamente em relação a esse projeto de liberdade que passava pelo reconhecimento da castração que incidiu a crítica de Foucault (1999b, 1990a) à psicanálise. A hipótese de uma repressão regulada por uma lei de interdição ao incesto seria duvidosa por três motivos: em primeiro lugar, ela não seria uma evidência histórica; em segundo, a mecânica do poder não seria de ordem repressiva, mas disciplinar, sendo exercida de maneira capilar sobre os corpos; por último, o discurso crítico que se dirige à repressão faria parte da mesma rede histórica que tal discurso busca denunciar (FOUCAULT, 1990a, p.15). Para o autor, o importante seria evidenciar a história das instâncias de produção discursiva, de produção de poder e de saber e, ainda, considerar as suas transformações (idem, p.17).

Com a crise da sociedade disciplinar (FOUCAULT, 1978; DELEUZE, 1992; HARDT \& NEGRI, 2000) e o anúncio do que é denominado como sociedade de controle ou do risco (BECK, 1986; DELEUZE, 1992; GIDDENS, 2002), os meios de confinamento — tais como a prisão, o hospital, a fábrica, a escola e a família 
- desterritorializaram-se, e os mecanismos de comando ficaram cada vez mais imanentes ao campo social, sendo distribuídos entre os corpos e os cérebros. Esse paradigma do poder tem uma natureza biopolítica, e se expressa como um controle que se estende a todas as relações sociais (FOUCAULT, 1999a).

Ora, se o desenvolvimento de um saber deve ser compreendido em relação às mudanças nos mecanismos de poder (FOUCAULT, [1978] 2003) e se, ao mesmo tempo, o saber e o poder estão interligados na produção da subjetividade, cabe indagar como as mudanças nas técnicas de poder transformam a experiência subjetiva. Pois, se há uma produção discursiva de saberes associada a mecanismos de poder que enunciam as formas de sofrer, há também efeitos desses jogos de verdade no modo pelo qual a experiência subjetiva é vivida. No entanto, é importante considerar que, para a clínica da psicanálise, é insuficiente dizer que os sujeitos, simplesmente, aderem aos jogos de verdade, uma vez que ali está presente alguém que sofre e busca um lugar para seu enunciado.

Por jogos de verdade Foucault entende o conjunto de regras de produção da verdade, jogos do verdadeiro e do falso, através dos quais o ser se constitui historicamente como experiência, podendo e devendo ser pensado (FOUCAULT, [1983] 2003, [1984] 2003). Pergunta o autor:

"Por meio de quais jogos de verdade o homem se pôs a pensar o seu ser próprio ao se perceber como louco, ao se olhar como doente, ao refletir sobre si mesmo como ser vivo, falante e trabalhador, ao se julgar e punir como criminoso? Através de quais jogos de verdade o ser humano se reconheceu como homem de desejo?" (FOUCAULT, [1983] 2003, p.195)

Quando se fala do aumento da depressão hoje, se por um lado há um sujeito que sofre singularmente, por outro, há também uma produção social da depressão, articulada a jogos de verdade específicos dos saberes médicos e psicológicos. Essa produção pode estar tanto ligada a uma designação de determinadas formas de sofrimento que já existiam e que são tratadas hoje como depressão, quanto ao desprestígio da experiência subjetiva do conflito. Esse desprestígio está acompanhado da valorização de processos de normalização em detrimento do inconsciente.

\section{SOCIEDADE DISCIPLINAR E SOLUÇÃO PATERNA}

De acordo com Foucault, as relações de poder estabelecidas no século XX nas instituições foram caracterizadas pela ordem disciplinar, cujo objetivo principal era a produção de corpos dóceis. Esses corpos deveriam ser eficazes, economicamente, e submissos, politicamente. Para atingir tal objetivo, a partir do final do 
século XVIII, os indivíduos foram distribuídos no espaço por meio de técnicas de enclausuramento e/ou de organizações hierárquicas, em que todas as atividades eram controladas ao longo do tempo. Com isso, as forças produtivas foram compostas para terem utilidade ao capitalismo vigente: as multidões confusas ou desorganizadas se transformavam, através de minuciosas práticas de poder, em multiplicidades organizadas. A intenção era dominar a diversidade, impondo-lhe uma ordem (FOUCAULT, 1977).

As técnicas de poder da organização social disciplinar no Ocidente estavam integradas a uma sociedade submetida à legislação criminal. Embora se possa considerar que há diferenças entre os sistemas legislativos nos diversos países, a organização disciplinar que torna o poder eficaz seria, para Foucault, comum (FOUCAULT, [1978] 2003, p.267).

As sociedades disciplinares substituíram as antigas sociedades de soberania. As primeiras tiveram seu início no século XVIII e atingiram seu ápice no século XX. No entanto, a partir do século XVII, já começava a aparecer uma nova mecânica do poder, com instrumentos novos e incompatíveis com as sociedades de soberania, que incidiam mais sobre os corpos do que sobre a terra e seus produtos. Surgia um mecanismo de poder exercido por vigilância, associado a uma rede de saberes médicos, pedagógicos e psicológicos, que permitia extrair dos corpos tempo e trabalho (FOUCAULT, 1999a).

A ortopedia social tentava tornar o exercício do poder, economicamente, o menos custoso possível, ligando o crescimento econômico ao rendimento dos aparelhos nos quais se exerce, sejam pedagógicos, militares, industriais ou médicos. Daí advinha a utilidade do modelo arquitetônico do panóptico de Jeremy Bentham.

O panóptico era um espaço fechado cuja vigilância podia atravessar todos os seus pontos, uma vez que em seu interior todos poderiam ser vistos. A inspeção era constante e o olhar estava alerta em toda parte: inseridos num lugar fixo, os indivíduos tinham os menores movimentos controlados e todos os acontecimentos registrados. Havia um trabalho ininterrupto de escrita que ligava o centro do panóptico à periferia, de acordo com uma figura hierárquica contínua, na qual cada um podia ser sempre localizado, examinado e distribuído em espaços específicos (FOUCAULT, 1977, p.173/4).

Assim, o panóptico funcionava como uma espécie de laboratório de poder, pois, graças a seus mecanismos de observação, ganhava em eficácia e em capacidade de penetração no comportamento dos homens. Pode ser compreendido como um modelo generalizável de funcionamento, um modo de definir as relações de poder com a vida cotidiana dos homens, tal como um "diagrama de um mecanismo de poder levado à sua forma ideal” (idem, p.181). Tal modelo servia às instituições médicas, militares, pedagógicas, e outras: 
“É polivalente em suas aplicações: serve para emendar os prisioneiros, mas também para cuidar dos doentes, instruir os escolares, guardar os loucos, fiscalizar os operários, fazer trabalhar os mendigos e os ociosos. É um tipo de implantação dos corpos no espaço, de distribuição dos indivíduos em relação mútua de organização hierárquica, de disposição dos centros e dos canais de poder, de definição de seus instrumentos e de modos de intervenção, que se podem utilizar nos hospitais, nas oficinas, nas escolas, nas prisões. 'Cada vez que se tratar de uma multiplicidade de indivíduos a que se deve impor uma tarefa ou um comportamento, o esquema panóptico poderá ser utilizado," (FOUCAULT, 1977, p.181)

Para que pudesse se adaptar à instituição pedagógica, o indivíduo já tinha sido preparado, ortopedicamente, no interior de sua família. A cada instituição cabiam determinadas tarefas normativas que facilitariam sua entrada na instituição subsequente: a família ensinava à criança as rotinas e regras iniciais ao bom comportamento; a escola aprimorava o trabalho com métodos contínuos de controle, vigilância e exame; a fábrica recebia o indivíduo ritmicamente adequado para se adaptar às regras da produção. Nas sociedades disciplinares, o indivíduo passava de um espaço fechado a outro, cada um com suas leis. As instituições tinham suas próprias regras e lógicas de subjetivação. Os territórios eram bem definidos, de forma que havia, por um lado, uma clara distinção entre o interior e o exterior institucional e, por outro, as funções que cabiam a cada instituição e a cada indivíduo eram bem determinadas (HARDT \& NEGRI, 2001).

A partir dessa definição dos lugares exercidos por cada um na sociedade disciplinar, podemos situar o Édipo como um complexo.

No complexo de Édipo masculino, a figura do pai media o reconhecimento da castração e se tornava um obstáculo aos investimentos desejantes na mãe. O investimento infantil sobre a mãe evolui para uma identificação com o pai, o que permite que a criança faça, futuramente, outras escolhas de objeto e novas identificações. Apesar de, para os dois sexos, a ligação com a mãe aparecer como o elemento comum inicial, segundo Freud, o menino sai do Édipo pela angústia de castração; a menina entra no Édipo pela descoberta da castração e pela inveja do pênis (FREUD, 1924).

Assim, após a prevalência inicial da mãe como objeto numa relação fusional, advém uma passagem necessária à prevalência do pai por meio de uma operação de separação entre a mãe e a criança. Essa separação será a condição da identificação sexuada do sujeito e de sua inscrição na ordem das gerações.

Com a leitura de Jacques Lacan da teoria do significante e das tópicas do simbólico, do imaginário e do real (LACAN, [1953] 2005), o complexo de Édipo foi definido como uma função simbólica, em que o pai interviria como uma lei para retirar a criança da fusão com a mãe. Em Lacan, o falo é o quarto elemento sobre 
o qual a triangulação edipiana deveria incidir, constituindo o centro de gravidade da função paterna que permite ao pai real assumir a sua representação simbólica como vetor da lei e da castração. Posteriormente, essa função foi enunciada por Lacan como Nome do Pai (LACAN, [1956] 1985, [1963] 2005). Ao dar um nome ao filho, o pai interviria junto a este como aquele que priva a mãe, dando origem ao ideal do eu da criança.

Tendo em vista o que foi exposto, cabe salientar o lugar ocupado pela função paterna como agente da lei na sociedade disciplinar. Assim, pode-se perguntar: levando em consideração o quadro disciplinar, para a psicanálise, o que está em jogo na teoria do pai? Para Michel Tort (2005, p.67), depois dos anos 1930, tratase do estatuto da feminilidade e da organização falocêntrica na vida psíquica; da natureza da paternidade e da maternidade em sua relação com a cultura ou a ordem simbólica; do estatuto da lei paterna em suas relações com a autoridade e as normas históricas. Em outras palavras, o Édipo e a figura paterna estão integrados às transformações de gênero e de sexo, e dizem respeito às mudanças da parentalidade e da filiação e às concepções de sexualidade que se sucedem.

Portanto, é na contramão do discurso que sustenta o declínio do poder paterno como responsável pelos males sociais que Michel Tort (2005), em seu livro Fin du dogme paternel, procura demonstrar como o pai faz parte de uma construção histórica solidária às formas tradicionais de dominação masculina que lhe asseguram o monopólio da função simbólica. Em crise no fim da modernidade, a figura patriarcal começa a ceder lugar, nas sociedades democráticas atuais, a novos arranjos parentais. Segundo o autor, não importa apenas representar a paternidade como uma realidade histórica, mas é necessário redefinir as condições de possibilidade de tal história.

Contudo, como distinguir, na elaboração psicanalítica do pai, o que corresponde às exigências da clínica e aquilo que reconduz a psicanálise ao “culto do pai”? De acordo com Tort, a pretensão à resolução do Édipo pela valorização da função paterna, implícita em Freud em sua exaltação da figura do pai, transformase explicitamente em solução psicanalítica em Lacan: é pela via da interdição paterna que as normas de acesso à cultura são definidas. Para o autor,

“o que está esquecido nesta operação é, de um lado, a natureza indomável dos processos inconscientes que se pretende ridiculamente normatizar; de outro, a natureza singular do tratamento psicanalítico, isto é, a experiência pela qual um indivíduo se vê confrontado com seus processos inconscientes”. (TORT, 2005, p.186) 


\section{A NOSTALGIA DO PAI}

Para Tort, a representação do declínio do pai traduz a nostalgia das tradições nas sociedades que se modificam, pois, ao invés de refletir a novidade do conjunto dessas transformações, tende-se a representar a história como a degradação da ordem anciã. Com isso, há uma naturalização das formas históricas dos dispositivos da família, da parentalidade, da sexualidade e da procriação (TORT, 2005, p.54). A partir dessa perspectiva, podemos dizer que importa menos ser contra ou a favor de um determinado exercício da paternidade, e mais, discutir como o pai é produzido e quais os enunciados de verdade associados a essa produção. ${ }^{2}$

Na configuração do Édipo constitui-se uma série de elementos interligados: o investimento do desejo nos pais, as identificações, a transformação dos dois tipos de ligação no curso da resolução edipiana, as tensões que se desdobram a partir desse processo. Por outro lado, esses elementos são integrados aos dados históricos correspondentes às variações das relações entre homens e mulheres, que modulam as representações paternas e maternas e as ordenam de maneira diferente a cada período histórico-social.

Assim, a transformação das normas de resolução do modelo edipiano que se articulam às novas posições maternas e paternas interliga-se à produção de novos arranjos psíquicos de subjetivação. Os novos arranjos, as modificações nas relações parentais, a redução do poder paterno não são, de forma necessária, uma ameaça à subjetivação, mas levam a um questionamento do esquema de referência ao pai.

“Contrariamente ao esquema repetido sobre o declínio do pai, o que está em jogo é a reposição em prol da exploração social dos fantasmas que presidiam a organização do 'simbólico' identificado à 'ordem dos Pais'. As transformações econômicas e políticas que produziram a individualização moderna colocaram em crise o assujeitamento imemorial do esquema de referência ao pai." (TORT, 2005, p.208)

Segundo Tort, há uma dificuldade dos psicanalistas em admitir, em nome do inconsciente, a contingência das relações de gênero e de sexo e a natureza histórica das concepções da parentalidade (p.68). Pois, se se admite que as condições atuais do poder paterno comprometem o Édipo, isso obriga a considerar que esse complexo requer o poder real dos pais. Portanto, em vez de pensar no lugar do pai ligado a uma fragilidade, o que levaria, consequentemente, à nostalgia

\footnotetext{
${ }^{2}$ Os enunciados de verdade diriam respeito às proposições ou afirmações conceituais ligadas à produção discursiva de determinado campo do saber. Pode-se dizer então que os enunciados de verdade (ou produções discursivas) fazem parte dos jogos de verdade que lhes instituem determinadas regras.
} 
do lugar de autoridade ocupado antes, pode-se potencializar sua transformação na atualidade:

\begin{abstract}
"Contudo, mais do que mobilizar a psicanálise para demonstrar, com tremores na voz, os efeitos 'catastróficos' dessa reviravolta histórica, é melhor constatar o que é correlativo da emergência de outra figura paterna, a do pai da criança (e não da família), figura ainda esboçada à pena (...). Não é a história de um declínio, mas de um nascimento violento como todos os nascimentos, de uma emergência. Enfim, um pai digno de seu nome!” (TORT, 2005, p.225)
\end{abstract}

\title{
A TRANSFORMAÇÃO DO LUGAR DO PAI E A DESTERRITORIALIZAÇÃO INSTITUCIONAL
}

"Há quatro ou cinco séculos, considerava-se que o desenvolvimento da sociedade ocidental dependia da eficácia do poder de preencher sua função. Por exemplo, importava na família como a autoridade do pai ou dos pais controlava os comportamentos dos filhos. O assunto importante era como o indivíduo obedecia. Nesses últimos anos, a sociedade mudou e os indivíduos também; eles são cada vez mais diversos, diferentes e independentes. Há cada vez mais categorias de pessoas que não estão submetidas à disciplina, de tal forma que somos obrigados a pensar o desenvolvimento de uma sociedade sem disciplina." (FOUCAULT, [1978] 2003, p.268)

Conforme indicamos, um aspecto importante na discussão do lugar do pai, hoje, diz respeito à mudança nas relações de poder na organização social. A desterritorialização dos meios de confinamento disciplinares fez com que os mecanismos de comando estivessem cada vez mais imanentes ao campo social, estendendose à totalidade das relações. Nessa medida, a lógica que funcionava dentro das paredes institucionais tende a se espalhar por todo o terreno social.

Na modernidade, os territórios institucionais eram bem definidos e formavam os indivíduos. As instituições tinham suas funções e regras de subjetivação delimitadas e havia uma clara distinção entre interior e exterior institucional. Contudo, na atualidade, o processo de produção da subjetividade parece não ser mais definido do mesmo modo: há uma progressiva indeterminação entre interior e exterior institucional, podendo-se afirmar que as instituições estão em crise (HARDT \& NEGRI, 2001, p.215-6).

A diluição dos limites institucionais aponta para a transformação no modo de circulação do poder. É nesse contexto que Hardt e Negri indicam uma nova forma de supremacia operante hoje, denominada pelos autores de Império. Este se caracteriza pela ausência de fronteiras territoriais, não se limitando a nenhuma 
região específica, e seu poder de comando funciona em todos os registros da ordem social.

A operação de comando do Império consiste em três momentos: o inclusivo, o diferencial e o gerencial. O primeiro momento assemelha-se a uma aceitação universal das diferenças, quando todos são aparentemente bem-vindos e acolhidos. Colocar de lado diferenças inadministráveis que podem originar conflitos significa, em realidade, tirar o potencial das diversas subjetividades constituintes: "o império não reforça suas fronteiras para afastar os outros; de preferência, puxa-os para dentro de sua ordem pacífica, como um poderoso vórtice” (HARDT \& NEGRI, 2001, p.218).

O momento diferencial do controle imperial compreende a afirmação das diferenças aceitas. As diferenças são culturais e contingentes, em vez de essenciais ou biológicas e, assim, pode-se tentar controlar e absorver os conflitos. A intenção é que as diferenças funcionem como força de pacífica identificação regional (idem, p.218-9).

A administração e hierarquização das diferenças sucedem o momento diferencial do Império, estabelecendo uma economia gerencial de comando. Esta não busca fixar as identidades, mas prosperar nos circuitos de mistura. A contingência, a mobilidade e a flexibilidade são aqui o verdadeiro poder do Império. As diferenças não precisam, em princípio, ser atenuadas ou negadas, mas afirmadas e, mesmo, festejadas, para serem ordenadas no aparelho de comando imperial. Podem, assim, ser neutralizadas (HARDT \& NEGRI, 2001).

A desterritorialização traz também implicações na forma de exercer o cuidado com o indivíduo. Se, na modernidade, cabia às instituições a fixação dos indivíduos e os cuidados com a educação, com a saúde e com o trabalho, pode-se dizer que hoje a ausência de funções específicas a cada instituição está articulada à imanência dos mecanismos de comando ao campo social e à totalidade das relações sociais. Assim, não cabe somente à família a socialização primária do filho - esta também é demandada à escola. Por sua vez, a tarefa formativa não se restringe à escola, pois o indivíduo deve entrar no circuito da formação permanente.

“A família, a escola, o exército, a fábrica não são mais espaços analógicos distintos que convergem para um proprietário, Estado ou potência privada, mas são agora figuras cifradas, deformáveis e transformáveis, de uma mesma empresa que só tem gerentes (...). O controle é de curto prazo e de rotação rápida, mas também contínuo e ilimitado, ao passo que a disciplina era de longa duração, infinita e descontínua. O homem não é mais o homem confinado, mas o homem endividado." (DELEUZE, 1992, p.224) 
No circuito da moratória ilimitada, o indivíduo está em permanente dívida consigo mesmo e com a sociedade. A desterritorialização acaba por deixá-lo à mercê de seus recursos e da absorção imperial. A condição da inclusão está associada à entrada no circuito do controle de si mesmo e no gerenciamento de seus riscos. Ora, se é o indivíduo que tem que saber a medida, de que lhe serviria uma lei de interdição exterior?

Segundo Tort (2005, p.217), a lógica da mudança no lugar do pai nos países ocidentais repercute as complexas evoluções dos jogos políticos dos estados democráticos após a Segunda Guerra Mundial. A partir da segunda metade do século XX, algumas características políticas podem ser evidenciadas, tais como: o recuo da perspectiva revolucionária; a predominância conflitual da problemática dos direitos humanos (correlativos ao empreendimento do capitalismo liberal); o fim da hierarquia tradicional das lutas políticas que fazem predominar o jogo do domínio prévio do poder econômico e seu correlato, a disseminação dos conflitos e das formas de luta; a emergência e o considerável desenvolvimento político do registro das relações de sexo e seus conflitos específicos.

Para o autor, não é suficiente examinar a solução paterna como uma construção teórica formulada pela psicanálise freudiana e desenvolvida por Lacan. Não se trata apenas de analisar o dispositivo fantasmático inconsciente da solução paterna, mas de examinar como ele pode ser colocado em questão na própria evolução das relações de autoridade no interior da família, na crítica à instituição familiar, nas controvérsias sobre os novos direitos das mulheres concernentes à procriação e nas polêmicas sobre as normas sexuais no quadro das estruturas de filiação (TORT, 2005).

A transformação do lugar do pai na atualidade pode, portanto, ser realçada. Se ela deve ser relacionada a uma rede de complexas mudanças político-sociais, não pode ser reduzida à questão do declínio de uma função de interdição que talvez não caiba mais nas relações parentais do Ocidente.

\section{PROCESSOS SUBJETIVOS E RELAÇÕES DE PODER NOS MODOS DE SOFRER E DE RESISTIR}

Ao discutir a questão das práticas regulatórias e normativas na produção do sexo, Judith Butler (1993) indica que o paradoxo da subjetivação reside justamente no fato de que o sujeito que resiste às normas é, ele próprio, possibilitado ou produzido por essas mesmas normas. Toda força regulatória e normativa se manifesta como uma espécie de poder produtivo, o poder de produzir os corpos que a força controla. O processo pelo qual as práticas regulatórias se materializam no corpo produz a reiteração, a renovação forçada das próprias normas. 
No entanto, ao invés de colocar o poder como origem da atividade, como se tivesse deslocado o sujeito, a autora aponta que existe apenas uma atuação sempre renovada, que é a do poder em sua persistência e instabilidade. E é essa instabilidade que marca um domínio no qual a força da lei regulatória pode se voltar contra si mesma, gerando rearticulações que colocam em questão a força hegemônica daquela mesma lei (BUTLER, 1993).

Talvez se possa considerar que os processos de subjetivação na clínica psicanalítica apontam justamente para essas rearticulações que colocam em questão a força hegemônica da lei regulatória. Assim, quando a disciplina buscava regular os corpos, o sofrimento subjetivo remetia às impossibilidades de uma obediência absoluta às normas e ao conflito interno gerado pelas interdições sexuais. No caso da histeria de conversão, por exemplo, pode-se afirmar seu poder de contestação encarnado no corpo como uma recusa à docilização disciplinar, ainda que à custa de uma dor interna. No caso da neurose obsessiva, em que a produção sintomática se liga a uma severidade moral cujas regras devem ser seguidas compulsivamente à risca, acaba-se por demonstrar também como a adequação exagerada à prescrição de normas está associada ao endurecimento interno, que, como Freud apontava, pode não ser desejável.

"Na investigação e na terapia das neuroses chegamos a fazer duas reprovações ao superego do indivíduo: com a severidade de seus mandamentos e proibições, ele se preocupa muito pouco com a felicidade deste, pois não leva em conta as resistências a sua obediência, a saber, a intensidade das pulsões do id e as dificuldades do mundo externo objetivo. Por isso, na tarefa terapêutica nos vemos necessitados frequentemente a combater o superego e rebaixar suas exigências. Objeções semelhantes podemos dirigir às exigências éticas do superego cultural. Também não se preocupa dos fatos da constituição mental dos seres humanos, proclama um mandamento e não se pergunta se poderá obedecê-lo. Pelo contrário, presume que ao ego do ser humano é possível tudo que lhe ordena, pois teria um governo irrestrito sobre o id. Isso é um erro, e nem sequer nos homens chamados normais o governo do id pode ser levado mais adiante de certos limites. Caso se exija mais, produz-se no indivíduo rebelião ou neurose, ou o torna infeliz.” (FREUD, [1930] 1982, p.138)

O sofrimento pode, assim, também ser entendido como um veículo de problematização e mesmo de resistência contra a hegemonia e a aderência às leis regulatórias. A resistência nesse caso não está sendo entendida como obstáculo ao tratamento psicanalítico, mas como potência de mudança subjetiva. Seria tal como um processo de singularização frente ao projeto social de hegemonia 
identitária, que mesmo recorrendo à produção sintomática, é também por meio dela que a enunciação do sujeito pode se fazer diferentemente. ${ }^{3}$

Aqui, o poder pode ser evidenciado como produtor dos corpos que busca controlar (BUTLER, 1993) e também como agenciador da luta interna contra o assujeitamento da identidade. Nesta perspectiva, para Negri (2002, p.45), foi Michel Foucault quem deu passos substanciais à frente de um conceito de poder que, em relação ao sujeito, apresenta dimensões construtivas e aberturas absolutas. O homem aparece assim como um conjunto de resistências que engendram uma capacidade de liberação:

“De fato, ele [Foucault] nos mostra que o sujeito é antes de tudo potência, produção. Certo, o sujeito pode ser reduzido a um puro fantasma, resíduo da totalidade dos sistemas de repressão: ainda assim ele é produtivo, mesmo neste horizonte redutor e dentro destes mecanismos! Isto porque, face a este limite, o sujeito retorna a si mesmo e ali redescobre o princípio vital.” (NEGRI, 2002, p.46)

Portanto, por um lado, pode-se colocar que o sofrimento e as formas de subjetivação associadas ao primeiro remetem aos processos de singularização que fazem frente ao assujeitamento da identidade. Por outro lado, na medida em que o sofrimento está interligado a uma experiência de dor e muitas vezes de aprisionamento sintomático, aquele vem também lembrar que o lugar da clínica da psicanálise é o de acolhimento das possibilidades de o sujeito se apresentar, enfrentando, junto a este, o projeto social da hegemonia identitária. Os dois lados sinalizam a potência produtiva da subjetividade que Negri parece apontar.

Para Ehrenberg (1998), Freud fez da neurose uma referência para enunciar os dilemas do homem moderno. Se, na cultura da interdição e da obediência, a inibição era normativamente visada, pois permitia moderar as ambições da massa, na cultura da performance e da ação individual, o indivíduo é colocado diante da necessidade de agir a qualquer custo e de se apoiar em sua força interna: ele está mais no circuito da iniciativa do que da obediência; sua questão seria menos o que é permitido fazer e mais o que é possível fazer.

Assim, pode-se dizer que a depressão ganha espaço quando o modelo disciplinar de gestão das condutas que gerencia as regras de autoridade e a conformi-

\footnotetext{
${ }^{3}$ O processo de singularização pode ser aproximado ainda ao que Foucault descreve como formas de subjetivação (FOUCAULT, [1983] 2004, 1990b). Segundo ele, a subjetivação está ligada à produção de modos de existência, à invenção de novas possibilidades de vida. Para que esses acontecimentos se efetuem, o indivíduo deve exercer modos de ação sobre si mesmo, por meio das técnicas de si. Estas são procedimentos que existem em toda civilização, pressupostos ou prescritos aos indivíduos para "fixar sua identidade, mantê-la ou transformá-la em função de determinados fins, graças a relações de domínio de si sobre si ou de conhecimento de si por si" (FOUCAULT, 1997, p.109).
} 
dade às interdições cede diante das normas que incitam à iniciativa individual e à imposição de autenticidade. Como consequência, se não há uma instância protetora, os riscos e a responsabilidade pela vida recaem sobre cada um. Com efeito, o que muitas vezes ocorre é um sentimento de impotência frente à exigência de autonomia: se na implosão depressiva o vazio da insuficiência está sendo denunciado, sua outra face está ligada à explosão aditiva e ao vazio da compulsão (EHRENBERG, 1998).

Nessa perspectiva, os ganhos com a liberdade se apresentam em detrimento de outras demandas: uma grande parte das pessoas, longe de se sentirem liberadas, foram, ao contrário, submetidas a novas formas de dependência e obrigadas a se confrontar com a solidão acrescida das exigências de autorrealização e de autonomia (BOLTANSKI \& CHIAPELLO, 1999). Diante do confronto com a solidão, o sujeito pode produzir pactos servis, seja com o estabelecimento de relações de submissão com o outro, seja pelos laços produzidos em instâncias religiosas, seja consumindo drogas de alívio para o sofrimento, ou mesmo consumindo bens materiais.

A prevalência do consumo pode ser vislumbrada na própria mudança na circulação do poder. O capitalismo do século XIX era de concentração para a produção e erigia a fábrica como meio de confinamento, sendo o capitalista o proprietário dos meios de produção; atualmente, o capitalismo não é dirigido para a produção, mas para a superprodução.

“Não compra mais matéria-prima e já não vende os produtos acabados: compra produtos acabados, ou monta peças destacadas. O que ele quer vender são serviços, e o que quer comprar são ações. Já não é um capitalismo dirigido para a produção, mas para o produto, isto é, para a venda ou para o mercado. Por isso ele é essencialmente dispersivo, a fábrica cedeu lugar para a empresa." (DELEUZE, 1992, p.223-4)

O problema que se coloca no capitalismo voltado para a superprodução é o do consumo dos bens produzidos em excesso. A questão agora seria o risco de consumir excessivamente sem se consumir ou adoecer. A mola da adição é colocada em movimento para o indivíduo consumir, mas é ele que precisa controlar os riscos da gula.

Por fim, é importante dizer que quando a proteção da figura do pai tradicional está em jogo, ou mesmo quando se fala da falência das instituições, coloca-se em pauta a questão do desamparo psíquico. Esse sentimento pode ser relacionado, segundo Freud, à necessidade de proteção do pai. Assim, ao comentar a origem da atitude religiosa, o autor diz: "Não poderia indicar na infância uma necessidade de força equivalente à de receber a proteção do pai” (FREUD, 1930, p.73). 
Contudo, não se trata de dizer que o desamparo é inerente ao homem, mas que a questão do desamparo esteve presente nos processos subjetivos da clínica psicanalítica da modernidade e que parece se incrementar com o projeto da pós-modernidade. Enunciar que o desamparo é um conceito importante para a teoria e a clínica psicanalítica não significa ligá-lo a uma natureza, mas sim afirmar que a forma como ele se apresenta hoje dá indícios das mudanças nos processos de subjetivação de nossos dias.

Nessa medida, a transformação do lugar do pai também poderia estar ligada ao lugar que o desamparo psíquico ocupa nas formas de sofrimento da atualidade. No entanto, é diferente dizer que a crença em um pai protetor acabou por incrementar o desamparo, ou que a crença no projeto da modernidade de dominação do mundo acabou por produzir o desamparo hoje - uma vez que este projeto seria impossível de ser realizado - e dizer que é o declínio do lugar do pai que aumenta não somente o desamparo, como também os males sociais contemporâneos. A associação imediata das mudanças da paternidade ao desamparo psíquico parece, por vezes, desconsiderar que o próprio lugar da função paterna também está relacionado à amplitude das metamorfoses político-sociais, e que este lugar também pode ser experienciado de outro modo.

Assim, acreditar que a figura tradicional do pai poderia assegurar a proteção da civilização e do sujeito talvez tenha sido uma das condições do projeto disciplinar da modernidade cujas impossibilidades e consequências se apresentam hoje. E se na sociedade disciplinar, a lei da função paterna estava interligada à produção de corpos dóceis, cujas figuras clínicas se evidenciavam na histeria e na neurose obsessiva, talvez se possa supor que a figura patriarcal da modernidade que sustentava a triangulação edípica também era uma produção histórica ligada às formas tradicionais de dominação masculina. No entanto, como diz Michel Tort (2005), o fim desse pai é o fim de um mundo, mas não o fim do mundo. Trata-se, portanto, de inventar outros modos de paternidade, de familiaridade e de filiação, sem remeter esse deslocamento à nostalgia de uma posição ocupada anteriormente que deveria ser reivindicada.

Recebido em 24/8/2009. Aprovado em 23/5/2010. 


\section{REFERÊNCIĀS}

BECK, U. (1998) La sociedad del riesgo. Buenos Aires: Paidós.

BOLTANSKI, L.; CHIAPELLO, È. (1999) Le nouvel esprit du capitalisme, Paris: Gallimard.

BUTLER, J. (1993) Bodies that matter: on the discursive limits of sex. New York: Routledge.

DELEUZE, G. (1992) Conversações. São Paulo: Ed. 34.

EHRENBERG, A. (1998) La fatigue d'être soi. Paris: Odile Jacob.

FOUCAULT, M. (1977) Vigiar e punir. Petrópolis: Vozes.

(1990a) História da sexualidade 1. A vontade de saber. Rio de Janeiro: Graal.

(1990b) História da sexualidade 2. O uso dos prazeres. Rio de Janeiro: Graal.

(1999a ) Em defesa da sociedade. São Paulo: Martins Fontes.

(1999b) A verdade e as formas jurídicas. Rio de Janeiro: Nau.

(2003) Ditos \& Escritos IV. Estratégia, poder-saber. Rio de Janeiro:

Forense Universitária.

(1978) "A sociedade disciplinar em crise", in Ditos \& Escritos IV. Estratégia, poder-saber. Rio de Janeiro: Forense Universitária, 2003.

. (2003) Ditos \& Escritos V. Ética, sexualidade, política. Rio de Janeiro: Forense Universitária.

. (1983) "O uso dos prazeres e as técnicas de si”, in Ditos \& Escritos V. Ética, sexualidade, política. Rio de Janeiro: Forense Universitária, 2003.

(1984) “A ética do cuidado de si como prática de liberdade”, in Ditos \& Escritos V. Ética, sexualidade, política. Rio de Janeiro: Forense Universitária, 2003.

FREUD, S. (1982) Obras completas. Buenos Aires: Amorrortu Editores.

(1924) “El sepultamiento del complejo de Edipo", v. XIX, p.177-188.

(1930) "El malestar en la cultura”, v. XXI, p.57-140.

GIDDENS, A. (2002) Modernidade e identidade. Rio de Janeiro: Jorge Zahar.

HARDT, M.; NEGRI, A. (2001) Império. São Paulo: Record.

LACAN, J. (2005) “Le symbolique, l’imaginaire et le réel” (1953), in Des noms-du-père. Paris: Seuil.

(1955-6/1985) O seminário — Livro 3: As psicoses. Rio de Janeiro, Jorge Zahar,.

. (2005) Des Noms-Du-Père (1963). Paris: Éditions du Seuil.

NEGRI, A. (2002) O poder constituinte - ensaio sobre as alternativas da modernidade, Rio de Janeiro: DP\&A.

ROUDINESCO, E.; PLON, M. (1998) Dicionário de psicanálise. Rio de Janeiro: Jorge Zahar.

TORT, M.(2005) Fin du dogme paternel. Paris: Aubier Psyc. 